\title{
Genotypic Variation in Senescence and Water Relations in Cut Flowers of Anthurium andraeanum (Hort.)
}

\author{
Aidan D. Farrell, Sarah Evelyn, Adrian M. Lennon, \\ and Pathmanathan Umaharan ${ }^{1}$ \\ Department of Life Sciences, Faculty of Science and Agriculture, The \\ University of the West Indies, St. Augustine Campus, College Road, The \\ Republic of Trinidad and Tobago
}

Additional index words. anthurium, vase life, cut flowers, senescence, water stress, water relations, water content, transpiration

\begin{abstract}
The role of water status in determining vase life was investigated in three Anthurium andraeanum Hort. cultivars: Spirit, Success, and Honduras. The cultivars were selected based on their vase life in previous studies and designated as ' $V_{\text {short }}$ ' ' $V_{\text {med }}$ ' and ' $V_{\text {long' }}$ respectively. A timeline experiment observing spadix necrosis (bloom degradation) under controlled conditions determined end of vase life as 15, 18, and 36 days for $V_{\text {short }}, V_{\text {med }}$ and $V_{\text {long }}$ respectively. Spathe relative water content (RWC) was closely associated with bloom degradation with all three cultivars reaching end of vase life at $\approx \mathbf{7 5} \%$ spathe RWC. Membrane integrity of the spathe showed no association with bloom degradation before the end of vase life with increased ion leakage found only after spadix necrosis was visible, indicating that bloom degradation was driven by spathe water status rather than senescence induced by other factors. RWC of the peduncle base and apex showed no association with bloom degradation in any of the cultivars. In fact, base and apex RWC remained high throughout the experiment despite the consistent loss of spathe RWC. This suggests that the reduced water content of the spathe was not induced by reduced hydraulic conductance of the peduncle. Stomatal conductance $\left(g_{S}\right)$ was highest in $V_{\text {short }}$ (approximately twice that of $V_{\text {long }}$ ) and likely contributed to the rapid loss of spathe RWC in this cultivar. However, $V_{\text {med }}$ and $V_{\text {long }}$ had similar $g_{\mathrm{S}}$ rates and water uptake rates despite large differences in spathe RWC. Thus, the two cultivars differed in their ability to retain water within the spathe tissue. In all three cultivars, end of vase life was determined by spathe water status. Genotypic variation in vase life was not driven by differences in the hydraulic conductance of the peduncle as previously thought. Differences in spathe water status were partially explained by differences in $g_{S}$ but other factors were also involved.
\end{abstract}

Anthurium (Anthurium andraeanum Hort.) is a herbaceous tropical perennial highly sought after on the world market as a cut flower. The bloom is composed of a modified bract (spathe) and a stalk-like inflorescence (spadix) supported on a peduncle (Dufour and Guérin, 2003). Cultivars are available in a range of vivid colors (white, green, orange, pink, and red) with equally vivid names ('Fantasia', 'Showbiz', 'Madame Butterfly', etc.). Among the most valued attributes of anthurium is its long vase life. Within the germplasm, vase life ranges from the extraordinarily long (e.g. greater than $40 \mathrm{~d}$ for 'Honduras') to the prohibitively short (e.g. less than $15 \mathrm{~d}$ for 'Spirit')

Received for publication 16 Apr. 2012. Accepted for publication 26 June 2012.

This work was sponsored by the University of the West Indies Campus Research and Publication Fund.

We thank Che Ferdinand, Kerth Daniels, and Tavia Bandoo for technical assistance in the laboratory and the management and staff of Kairi Blooms Farm for providing the anthurium blooms.

${ }^{1}$ To whom reprint requests should be addressed; e-mail pathmanathan.umaharan@sta.uwi.edu.
(Elibox and Umaharan, 2010). The mechanisms regulating this variation in vase life are unknown, limiting the ability of breeders to select for this trait.

Elibox and Umaharan (2008) found that deterioration of vase life in anthurium is associated with loss of spathe glossiness, spathe wilting, spathe blueing, and necrosis of the spathe and spadix. Spadix necrosis was the first visible indication of deterioration of vase life for most cultivars and hence is the best index for cultivar comparisons. A number of studies have established an association between anthurium vase life and the water relations of the cut flower (Elibox and Umaharan, 2010; Mujaffar and Sankat, 2003; Paull et al., 1985). Similar associations have been found in other species and can result from either an obstruction in water transport or a reduced ability to retain water in the floral organ as senescence begins (Solomos and Gross, 1997). As such, genotypic variation in vase life may be driven by water supply or by the senescence response in the bloom. It is currently unclear whether deterioration of the anthurium cut flower is the result of the direct effect of water loss or is mediated by a senescence response in the bloom.
Several authors have suggested that deterioration of vase life in anthurium is "probably" as a result of occlusion of the vascular system at the base of the peduncle, possibly associated with the cutting of the bloom (Higaki et al., 1994; Paull et al., 1985; Paull and Goo, 1982). Elibox and Umaharan (2010) found that genotypic variation in vase life was associated with differences in the pattern of water uptake from the vase, which led the authors to suggest that the extent of occlusion may be a factor in determining water uptake. However, although occlusion has been shown to occur in cut flowers of other species [e.g. rose (Rosa hybrida L.; Ichimura et al., 1999) and chrysanthemum (Dendranthema grandiflora Ramat.; van Doorn and Cruz, 2000)], there is no direct evidence from these studies that occlusion is the major determinant of loss of vase life in anthurium.

Vase life has been shown to be associated with the rate of water loss through transpiration from the spathe and spadix (Elibox and Umaharan, 2008, 2010; Mujaffar and Sankat, 2003; Paull et al., 1985). Elibox and Umaharan (2010) found that the dynamics of water loss explained a large proportion of the genotypic variation in vase life.

We evaluate bloom water status by combining measurements of water uptake from the vase with direct measurements of $g_{\mathrm{S}}$ from the spathe as well as measurements of RWC from the spathe and from the base and apex of the peduncle. Physiological senescence is assessed through visual observation of the spadix and by measuring the membrane integrity of the spathe tissue. Our objectives were to determine whether loss of vase life is controlled by bloom water status or by physiological senescence and to determine the extent to which genotypic variation in vase life is explained by bloom water relations.

\section{Materials and Methods}

Plant material. Three anthurium cultivars were used, namely 'Spirit', 'Success', and 'Honduras', designated as ' $V_{\text {short }}$, ' $V_{\text {med }}$ ' and ' $V_{\text {long }}$ ' respectively, based on the vase life estimates of Elibox and Umaharan (2010). All experiments were carried out using cut flowers collected from a commercial anthurium farm (Kairi Blooms Ltd., Arima, Trinidad \& Tobago). Blooms with 33\% mature spadix, straight peduncles, and no deformities were selected for experimentation and were transported to the laboratory in an insulated box with the peduncle ends held in tap water. In the laboratory, blooms were recut underwater to a peduncle length of $30 \mathrm{~cm}$ with a new razor blade. Blooms were placed in a $250-\mathrm{mL}$ graduated cylinder with $210 \mathrm{~mL}$ of deionized water. The cylinders were partially covered in aluminium foil to prevent microbial growth and topped up weekly to maintain the water level. For convenience, two blooms of the same cultivar were sometimes placed in the same cylinder (although only where water uptake from the vase was not being measured). The blooms 


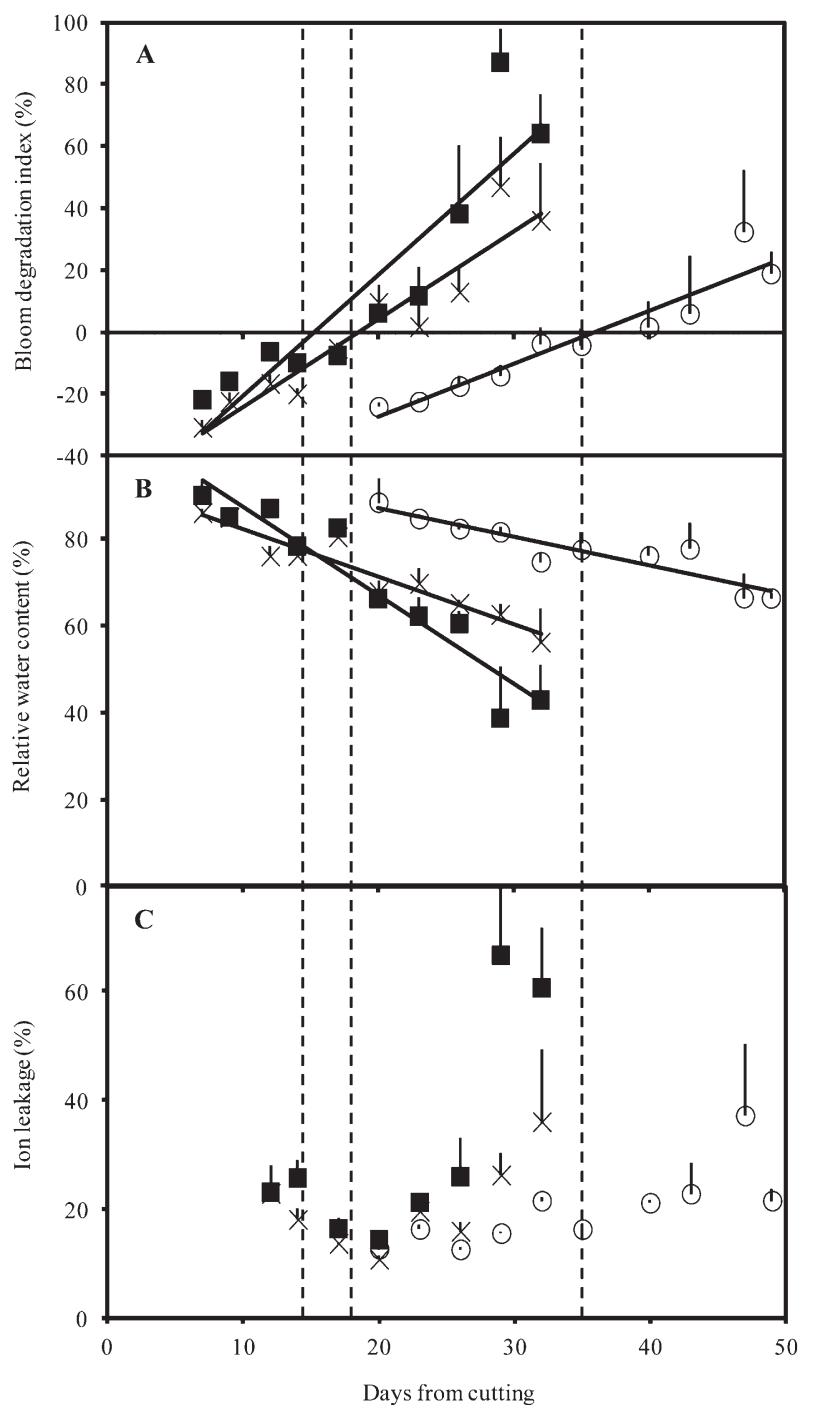

Fig. 1. Timeline of (A) bloom degradation, (B) relative water content, and (C) ion leakage in short (squares), medium (crosses), and long (circles) vase life anthurium cultivars. Bloom degradation is measured as a bloom degradation index, in which percent necrosis (positive values) or percent greenness (negative values) is scored. End of vase life, indicated by dashed lines, was designated as the day when the mean bloom degradation index reached zero. Data are means with $\pm \mathrm{SE}$ from six blooms.

were randomized and placed in a controlled environment room at $22 \pm 2{ }^{\circ} \mathrm{C}$ under florescent light. The sampling period for each cultivar was based on the results of previous studies and encompassed the period when rapid bloom degradation occurs (Elibox and Umaharan, 2010). During the sampling period, destructive harvests were taken initially every Monday, Wednesday, and Friday and were then adjusted depending on observed bloom degradation.

Experimentation. Two vase life timeline experiments were conducted under controlled conditions. Expt. 1 monitored bloom degradation, spathe RWC, and spathe membrane integrity in the three cultivars. Sixty blooms of each cultivar were fully randomized within the controlled environment room and six randomly selected blooms of each cultivar were harvested on each of the 10 sampling days. Expt. 2 monitored the RWC of the spathe and of the peduncle base and apex. Seventy-two blooms of each cultivar were fully randomized within the controlled environment room and six randomly selected plants of each cultivar were harvested on each of the 12 sampling days or until end of vase life was reached. Expt. 2 also included measurements of bloom degradation, $g_{\mathrm{S}}$, and water uptake from the vase that were taken from a separate set of 11 blooms. These 11 blooms were randomly selected at the start of the experiment and monitored until end of vase life was reached.

Observation of bloom degradation. Previous studies have shown that spadix necrosis is a strong indicator of overall bloom degradation across many anthurium cultivars (Elibox and Umaharan, 2010). A bloom degradation index (BDI) was devised based on percent necrosis observed on the spadix recorded to the nearest $5 \%$. When the spadicies were immature, the percent greenness was recorded with $5 \%$ green area scored as $-5 \%$ BDI. As the blooms aged and green areas diminished, the percentage visible spadix necrosis was recorded with $5 \%$ necrotic areas scored as $+5 \%$ BDI. This resulted in a continuous linear scale that allowed comparisons between cultivars with different bloom degradation rates. End of vase life was designated as the day when the mean BDI reached 0 , i.e., first visible sign of spadix necrosis in an average bloom.

Ion leakage and relative water content. At each harvest date, six blooms were selected at random for determination of ion leakage and RWC. Blooms were rinsed with deionized water and eight discs were removed from the spathe using an $8-\mathrm{mm}$ borer. The discs were chosen from each side of the midrib and proximal to it.

The eight discs were weighed to determine fresh weight using a microbalance (XX70 Precision Balance; Denver Instruments, New York, NY) and placed in a vial containing $15 \mathrm{~mL}$ of deionized water. The vials were then placed in the dark on a shaker for $24 \mathrm{~h}$ at room temperature $\left(22{ }^{\circ} \mathrm{C}\right)$. A timeline experiment carried out previously showed that $24 \mathrm{~h}$ allowed for accurate estimation of both ion leakage and RWC with saturated weight and conductivity having reached a plateau (data not shown). After $24 \mathrm{~h}$, the discs were removed from the vials and placed between two sheets of filter paper for $\approx 1 \mathrm{~min}$ to remove excess water before being weighed to determine the saturated weight.

The discs were then oven-dried for $24 \mathrm{~h}$ at $70{ }^{\circ} \mathrm{C}$, placed in a room temperature desiccator for 10 to $15 \mathrm{~min}$, and then weighed (dry weight). RWC was calculated as:

\section{Relative water content $=$ \\ (fresh weight - dry weight)/ \\ (saturated weight - dry weight $) \times 100$}

For ion leakage, the conductivity of the solution in the vials was measured after the $24 \mathrm{~h}$ incubation (Oakton, P700 bench meter with automatic temperature compensation; IL). The discs were then returned to the vials and autoclaved for $15 \mathrm{~min}$ to achieve cell lysis, after which conductivity was measured again. Ion leakage was calculated as:

$$
\begin{aligned}
& \text { Ion leakage }= \\
& (\text { conductivity before autoclaving/ } \\
& \text { conductivity after autoclaving }) \times 100
\end{aligned}
$$

For Expt. 2, in addition to the eight discs collected from the spathe, eight segments were removed from the base and apex of the peduncle. Segments were removed by cutting $5-\mathrm{mm}$ sections from the peduncle starting $1 \mathrm{~cm}$ from the cut surface (base) and immediately adjacent to the spathe (apex). These were used for determination of RWC using the method outlined previously.

Water uptake and stomatal conductance. Water uptake was estimated by observing water loss from the graduated cylinder expressed as water uptake per bloom. $g_{\mathrm{S}}$ was measured using a porometer, measuring from the abaxial side of the bloom avoiding major 

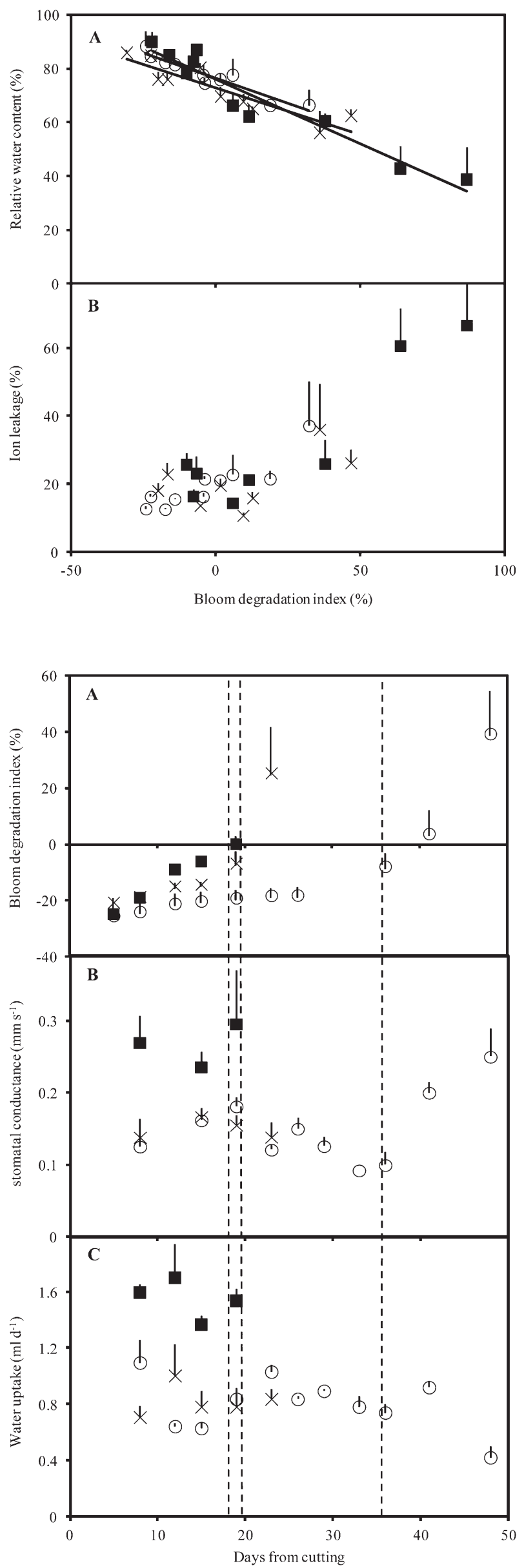

Fig. 2. The relationship between (A) bloom degradation and relative water content and (B) bloom degradation and ion leakage in short (squares), medium (crosses), and long (circles) vase life anthurium cultivars. Bloom degradation is measured as a bloom degradation index, in which percent necrosis (positive values) or percent greenness (negative values) is scored. Lines show best fit linear models fitted to the means for bloom degradation index and relative water content in short $(y=-0.47 x+76.1$; $\left.R^{2} 91 \%, P<0.001\right)$, medium $(y=-0.35 x+$ $\left.72.78 ; R^{2} 81 \%, P<0.001\right)$, and long $(y=-0.37 x+$ $\left.76.4 ; R^{2} 89 \%, P<0.001\right)$ vase life cultivars. Data are means with \pm SE from six blooms.
Fig. 3. Timeline of (A) bloom degradation, (B) water uptake, and (C) stomatal conductance $\left(g_{\mathrm{S}}\right)$ in short (squares), medium (crosses), and long (circles) vase life anthurium cultivars. Bloom degradation is measured as a bloom degradation index, in which percent necrosis (positive values) or percent greenness (negative values) is scored. End of vase life, indicated by dashed lines, was designated as the day when the mean bloom degradation index reached zero. Data are means with \pm SE from 11 blooms. 


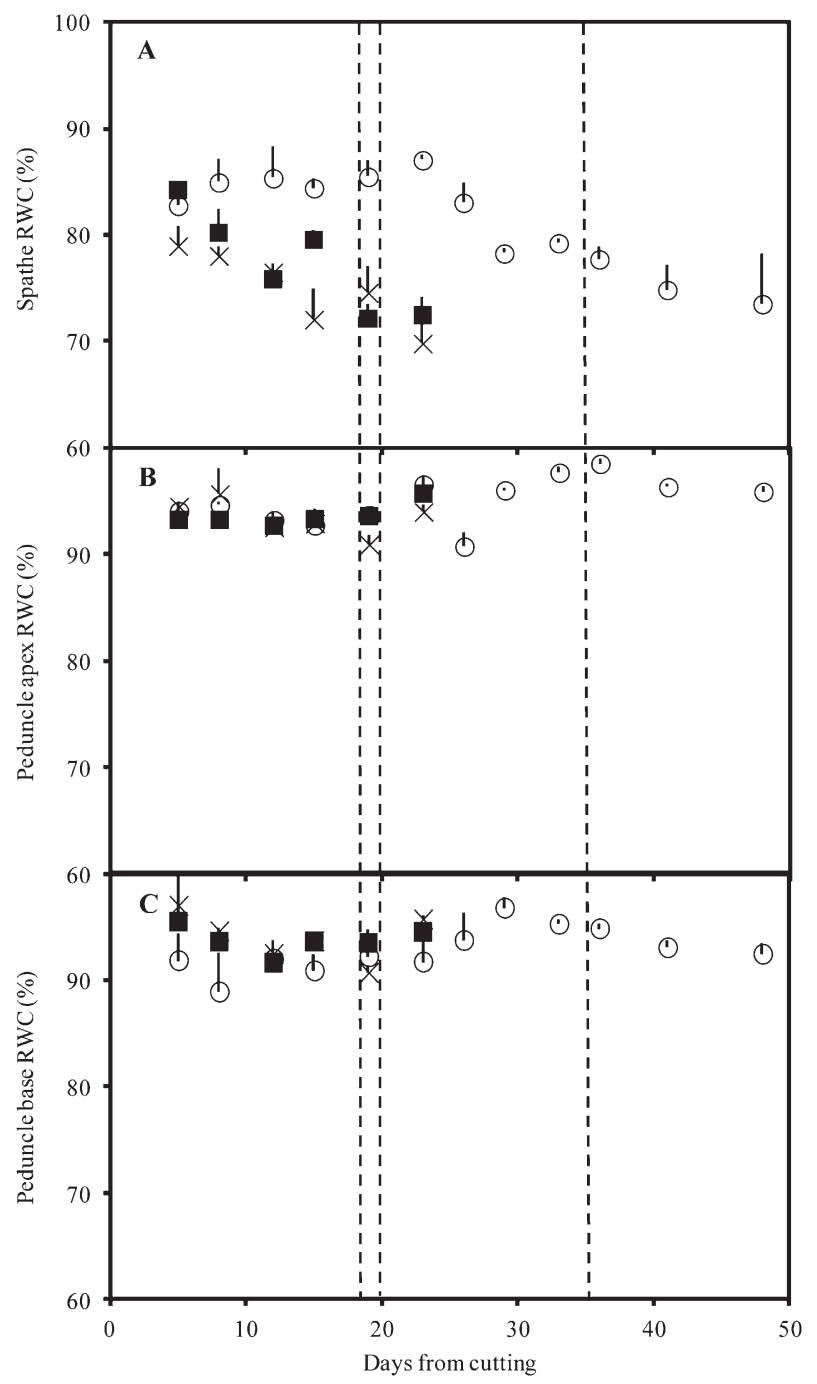

Fig. 4. Timeline of relative water content (RWC) in (A) spathe, (B) peduncle apex, and (C) peduncle base in short (squares), medium (crosses), and long (circles) vase life anthurium cultivars. Dashed lines indicate end of vase life in each cultivar (see Fig. 3). Data are means with $\pm \mathrm{SE}$ from six blooms.

veins and degraded areas (AP4; Delta-T, Cambridge, U.K.).

\section{Results and Discussion}

Expt. 1: Bloom degradation, senescence, and spathe water content. All three cultivars showed a linear increase in the BDI over time (Fig. 1A). Using a best fit linear function for the short, medium, and long vase life cultivars (' $V_{\text {short }}$,' ' $V_{\text {med }}$ ' and ' $V_{\text {long }}$ ), the end of vase life was determined as 15,18 , and $36 \mathrm{~d}$, respectively. These times are similar to the vase life estimates determined for these cultivars by Elibox and Umaharan (2010). All three cultivars showed a linear decrease in spathe RWC over time (Fig. 1B) with the timing and rate of decline corresponding to the rate of bloom degradation across the cultivars. For all cultivars, spathe RWC began to fall before any visible signs of bloom degradation were observed. In all three cultivars, end of vase life occurred when spathe RWC reached $\approx 75 \%$ $\left(77 \%, 73 \%\right.$, and $76 \%$ for $V_{\text {short }}, V_{\text {med }}$ and $V_{\text {long }}$ respectively). A correlation analysis of spathe RWC and BDI, correcting for cultivar differences in timing of bloom degradation, found a strong linear relationship with no clear difference between the cultivars (Fig. 2A). Best fit linear models fitted to the means for $\mathrm{BDI}$ and RWC were adequate for all cultivars: short $\left(y=-0.47 x+76.1 ; R^{2} 91 \%, P<0.001\right)$, medium $\left(y=-0.35 x+72.78 ; R^{2} 81 \%, P<\right.$ $0.001)$, and long $\left(y=-0.37 x+76.4 ; R^{2} 89 \%\right.$, $P<0.001$ ) (Genstat 12; VSN International Ltd., Hemel Hempstead, U.K.). These results demonstrate a tight physiological link between spathe RWC and bloom degradation for all three cultivars. The difference in the timing of bloom degradation between cultivars is accounted for by the differing ability of the cultivars to maintain their RWC over time.

In contrast to spathe RWC, ion leakage showed no association with bloom condition before the end of vase life (Figs. 1C and 2B). For all cultivars, ion leakage before the end of vase life was below 20\% (apart from initial rates of $20 \%$ to $30 \%$ for $V_{\text {short }}$ and $V_{\text {med }}$ ), indicating that membrane integrity was maintained in the period leading to spadix necrosis. Once necrosis began, ion leakage showed a linear or greater-than-linear increase in all cultivars with the timing and rate of increase corresponding to the rate of bloom degradation across the cultivars (Fig. 2B). This contrasts with the senescence induced by chilling of anthurium spathe tissue where increased ion leakage was observed before visible symptoms of bloom degradation (Promyou et al., 2012). Although ion leakage appears to be a sensitive indicator of senescence once spadix necrosis begins, the timing of the response in all three cultivars suggests that loss of membrane integrity occurs simultaneously with end of vase life and is thus unlikely to be a causal factor.

Expt. 2: Bloom degradation and bloom water relations. The timeline of bloom degradation in Expt. 2 was similar to that observed in Expt. 1, although the rate of degradation was generally lower (Fig. 3), particularly in $V_{\text {short }}$ in which a slow degradation resulted in end of vase life occurring at a similar date to $V_{\text {med }}$. Like in Expt. 1, there was a clear association between bloom degradation and spathe RWC. Best fit linear models fitted to the means for BDI and RWC were adequate for all cultivars: short $\left(y=-0.25 x+74.65 ; R^{2} 60 \%\right.$, $P<0.05)$, medium $\left(y=-0.19 x+73.33 ; R^{2}\right.$ $95 \%, P<0.005)$, and long $(y=-0.20 x+78.69$; $R^{2} 79 \%, P<0.001$ ) (Genstat 12; VSN International Ltd., Hemel Hempstead, U.K.). Figure 4 shows the timeline for RWC of the spathe, the peduncle apex, and the peduncle base. The earlier sampling period used in Expt. 2 highlights a clear lag period of $\approx 20 \mathrm{~d}$ before $V_{\text {long }}$ shows any reduction in BDI or spathe RWC. There was no association between bloom degradation and base or apex RWC with both remaining high throughout the experiment in all cultivars. This suggests that there is no limitation in water conductance through the peduncle and that any limitation in the supply of water to the spathe occurs within the spathe itself. This contrasts with the results of Williamson and Milburn (1995) who found that deterioration of vase life in Acacia amoena flowers was associated with a reduction in hydraulic conductance and RWC of the stem apparently resulting from cavitation. Our conclusion does not support the previous suggestion that water stress in the anthurium spathe is the result of occlusion at the base of the peduncle (Elibox and Umaharan, 2010; Higaki et al., 1994; Paull et al., 1985; Paull and Goo 1982). Paull et al. (1985) monitored percentage water content of the spathe, spadix, and peduncle in anthurium ('Ozaki Red') for $20 \mathrm{~d}$ after cutting and found that both spathe and peduncle showed a small (less than 3\%) decrease in percentage water content. Although the time scale was shorter than that used here, the results of Paull et al. (1985) are similar in that the spathe water content appears to drop more rapidly than that of the peduncle. It is likely that occlusion does occur in some cases, in particular where less sterile conditions are used, but our results suggest that occlusion is not the principle cause of end of vase life in anthurium. Furthermore, the lack of correlation between apex RWC and vase life across the three cultivars suggests 
propensity for occlusion is not responsible for the genotypic variation in vase life observed in anthurium.

Figure $3 \mathrm{~B}-\mathrm{C}$ shows the timeline for water uptake and $g_{\mathrm{S}}$ in each of the cultivars. All three cultivars were able to maintain a flow of water from the cylinder: through the peduncle and the spathe's vascular system and through the stomata to the atmosphere. The pattern of water uptake is similar to that seen in Elibox and Umaharan (2010) and Paull et al. (1985) with blooms showing a decline in the rate of water uptake over the initial $20 \mathrm{~d}$ before reaching a plateau. This decline in water uptake after cutting is common in many cut flowers (van Doorn, 1997). As seen by Elibox and Umaharan (2010), $V_{\text {short }}$ shows higher rates of water uptake than the other cultivars over the initial $20 \mathrm{~d}$ after cutting. The results for $V_{\text {short }}$ support the suggestion that high $g_{\mathrm{S}}$ is associated with short vase life. This conclusion is further supported by experiments showing that application of antitranspiration waxes to anthurium blooms reduces the rate of water uptake during bloom degradation and can extend the vase life by as much as $18 \mathrm{~d}$, although the general pattern of declining water uptake over the initial $20 \mathrm{~d}$ remains (Mujaffar and Sankat, 2003; Paull et al., 1985). Furthermore, Elibox and Umaharan (2008) showed that variation in stomatal density partially explained differences in vase life observed in anthurium cultivars.

The rate of water uptake by the bloom is influenced by $g_{\mathrm{S}}$ per unit area and by bloom size. In this study, $V_{\text {med }}$ and $V_{\text {long }}$ blooms were of similar dimensions, whereas $V_{\text {short }}$ blooms were considerably larger (data not shown). The results show that $V_{\text {short }}$, which had the largest blooms, had the highest rate of water uptake (approximately twice that of $V_{\text {long }}$ blooms). $V_{\text {short }}$ also had appreciably higher $g_{S}$ per unit area (approximately twice that of $V_{\text {long }}$ blooms). The relatively rapid loss of water corresponds with the rapid reduction in spathe RWC in $V_{\text {short }}$. It is likely that the rapid loss of spathe RWC in these blooms is related to the relatively high $g_{\mathrm{S}}$.

Mujaffar and Sankat (2003) found a rapid decrease in moisture content from $15 \mathrm{~d}$ after cutting in anthurium ('Trinidad Pink'). They determined that the loss of moisture content was dependent on the ratio of water loss (through transpiration) to water uptake (from the vase) with blooms maintaining a positive water balance when the ratio of transpiration to water uptake was less than 1.5. They also showed that both bloom moisture content and vase life can be extended using antitranspiration waxes. Our results support the suggestion that transpiration rate is an important determinant of vase life and of genotypic variation in vase life. However, it should be noted that the rates of water uptake and $g_{\mathrm{S}}$ were similar for $V_{\text {med }}$ and $V_{\text {long }}$ throughout the experiment despite marked differences in the spathe RWC of these two cultivars (Figs. 3 and 4). Equally, the large difference in $g_{\mathrm{S}}$ between $V_{\text {short }}$ and $V_{\text {med }}$ coincides with a relatively small difference in spathe RWC. Across the three cultivars there is a decoupling of water uptake and spathe RWC, which suggests that the loss of water from spathe cells, although driven by transpiration, is regulated by the ability of cells to compete with the transpirational stream. There is no indication that $V_{\text {short }}$ or $V_{\text {med }}$ are unable to maintain hydraulic conductance to the spathe; on the contrary, $V_{\text {short }}$ can only maintain a higher rate of water uptake from the cylinder by maintaining a higher rate of hydraulic conductance. $V_{\text {long }}$ appears better able to retain water in the bulk spathe tissue over time, particularly during the 20 -d lag period. This ability to retain water in the bulk tissue that is not part of the transpirational stream suggests an enhanced ability to maintain a favorable water potential. The ability to maintain a negative water potential can be influenced by the osmotic concentration of a bloom and enhanced vase life has been associated with control of osmotic potential in other cut flowers (Mayak et al., 1978; van Doorn, 1997). In effect, cut flowers that have the ability to maintain or synthesize solutes within the cells of the floral organs are buffered from the impact of transpiration because the transpired water comes preferentially from the vase. It is likely that this mechanism accounts for some of the variation in vase life observed here.

Overall, our results suggest that vase life is determined by the water relations of the spathe and spadix. The difference in vase life between $V_{\text {short }}$ and $V_{\text {med }}$ appears to be driven by the higher rate of transpiration in $V_{\text {short }}$ whereas the difference in vase life between $V_{\text {med }}$ and $V_{\text {long }}$ appears to be driven by an enhanced ability to retain water in the spathe in $V_{\text {long. }}$.

\section{Literature Cited}

Dufour, L. and V. Guerin. 2003. Growth, developmental features and flower production of $A n$ thurium andreanum Lind. in tropical conditions. Scientia Hort. 98:25-35.

Elibox, W. and P. Umaharan. 2008. Morphophysiological characteristics associated with vase life of cut flowers of anthurium. HortScience 43:825-831.

Elibox, W. and P. Umaharan. 2010. Cultivar differences in the deterioration of vase-life in cut-flowers of Anthurium andraeanum is determined by mechanisms that regulate water uptake. Sci. Hort. 124:102-108.

Higaki, T., J.S. Lichty, and D. Moniz. 1994 Anthurium culture in Hawaii. University of Hawaii Research Extension Series 152:1-22.

Ichimura, K., K. Kojima, and R. Goto. 1999. Effects of temperature, 8-hydroxyquinoline sulphate and sucrose on the vase life of cut rose flowers. Postharvest Biol. Technol. 15:3340.

Mayak, S., A.M. Kofranek, and T. Tirosh. 1978. The effect of inorganic salts on the senescence of Dianthus caryophyllus flowers. Physiol. Plant. 43:282-286.

Mujaffar, S. and C. Sankat. 2003. Effect of waxing on the water balance and keeping qualities of cut anthuriums. International Agrophysics 17: $77-84$.

Paull, R.E., N.J. Chen, and J. Deputy. 1985. Physiological changes associated with senescence of cut anthurium flowers. J. Amer. Soc. Hort. Sci. 110:156-162.

Paull, R.E. and T. Goo. 1982. Pulse treatment with silver nitrate extends vase life of anthuriums. J. Amer. Soc. Hort. Sci. 107:842-822.

Promyou, S., S. Ketsa, and W.G. van Doorn. 2012 Salicylic acid alleviates chilling injury in anthurium (Anthurium andraeanum L.) flowers. Postharvest Biol. Technol. 64:104-110.

Solomos, T. and K.C. Gross. 1997. Effects of hypoxia on respiration and the onset of senescence in cut carnation flowers (Dianthus caryophyllus L.). Postharvest Biol. Technol. 10:145-153.

van Doorn, W.G. 1997. Water relations of cut flowers. Hort. Rev. 18:1-85.

van Doorn, W.G. and P. Cruz. 2000. Evidence for a wounding-induced xylem occlusion in stems of cut chrysanthemum flowers. Postharvest Biol. Technol. 19:73-83.

Williamson, V.G. and J.A. Milburn. 1995. Cavitation events in cut stems kept in water: Implications for cut flower senescence. Sci. Hort. 64:219-232. 